\title{
Vitamin C and Its Emerging Role in Pain Management: Beneficial Effects in Pain Conditions Besides Post Herpetic Neuralgia
}

Mechanicsville, VA, USA

Shailendra Kapoor, MD

\section{TO THE EDITOR}

I found the recent article by Byun highly interesting [1]. Notably, the past few years have seen the emergence of vitamin $\mathrm{C}$ as a potent anti-nociceptive agent in the management of a number of painful conditions in addition to postherpetic neuralgia.

For instance, Zollinger et al. [2], in a recent double blind randomized study, have demonstrated that the risk of reflex sympathetic dystrophy following wrist fractures is significantly attenuated following post-fracture administration of ascorbic acid. Similarly, pre-administration of vitamin $\mathrm{C}$ prior to foot and ankle surgeries decreases the risk of developing complex regional pain syndrome (CRPS) I [3]. For example, in one study, vitamin $\mathrm{C}$ administered at a daily dosage of $500 \mathrm{mg}$ starting 2 days prior to total trapeziometacarpal joint prosthetic surgery and continued for 7 weeks post op was associated with no reported cases of CRPS I [4].

Vitamin C may also have a role to play in migraine prophylaxis [5]. In a similar way, vitamin $C$, by virtue of its antioxidant properties, significantly mitigates pain and increases the pain threshold in patients with chronic pancreatitis [6]. The pain-attenuating efficacy of vitamin $\mathrm{C}$ is further enhanced when it is used in concert with other agents such as B-carotene and methionine.

Vitamin C exerts its anti-nociceptive effects primarily as a result of its antioxidant properties. It is clear that vitamin $\mathrm{C}$ has a major role to play in mitigating pain in a number of clinical conditions in addition to postherpetic neuralgia.

\section{REFERENCES}

1. Byun $\mathrm{SH}$, Jeon $\mathrm{Y}$. Administration of vitamin $\mathrm{C}$ in a patient with herpes zoster - A case report -. Korean J Pain 2011; 24: 108-11.

2. Zollinger PE, Tuinebreijer WE, Kreis RW, Breederveld RS. Effect of vitamin $\mathrm{C}$ on frequency of reflex sympathetic dystrophy in wrist fractures: a randomised trial. Lancet 1999; 354: 2025-8.

3. Besse $J$, Gadeyne S, Galand-Desmé S, Lerat JL, Moyen B. Effect of vitamin $C$ on prevention of complex regional pain syndrome type I in foot and ankle surgery. Foot Ankle Surg 2009; 15: 179-82.

4. Zollinger PE, Ellis ML, Unal $H$, Tuinebreijer WE. Clinical outcome of cementless semi-constrained trapeziometacarpal arthroplasty, and possible effect of vitamin $\mathrm{C}$ on the occurrence of complex regional pain syndrome. Acta Orthop Belg 2008; 74: 317-22.

Received April 19, 2012. Revised May 15, 2012. Accepted May 29, 2012.

Correspondence to: Shailendra Kapoor, MD

Mechanicsville, VA, USA

Tel: +1-8656785678, Fax: +1-8656071014, E-mail: shailendrakapoor@yahoo.com

() This is an open-access article distributed under the terms of the Creative Commons Attribution Non-Commercial License (http:// creativecommons.org/licenses/by-nc/3.0/), which permits unrestricted non-commercial use, distribution, and reproduction in any medium, provided the original work is properly cited.

Copyright (C) The Korean Pain Society, 2012 
5. Visser EJ. Is migraine a complex regional pain syndrome of the brain? Migraine prophylaxis with vitamin C? Pain Pract 2011; 11: 199-200.

6. De las Heras Castaño G, García de la Paz A, Fernández MD,
Fernández Forcelledo $\mathrm{JL}$. Use of antioxidants to treat pain in chronic pancreatitis. Rev Esp Enferm Dig 2000; 92: 37585. 